\title{
Risk Factors for Placenta Accreta: A Large Prospective Cohort
}

\author{
Zachary S. Bowman, MD, PhD ${ }^{1}$ Alexandra G. Eller, $\mathrm{MD}^{1} \quad$ Tyler R. Bardsley, $\mathrm{MS}^{2} \quad$ Tom Greene, $\mathrm{PhD}^{2}$ \\ Michael W. Varner, $\mathrm{MD}^{1}$ Robert M. Silver, MD ${ }^{1}$ \\ 1 Department of Obstetrics and Gynecology, University of Utah Health \\ Sciences Center and Intermountain Healthcare, Salt Lake City, Utah \\ 2 Division of Epidemiology, Department of Internal Medicine, \\ University of Utah Health Sciences Center, Salt Lake City, Utah \\ Address for correspondence Zachary S. Bowman, MD, PhD, \\ Department of Obstetrics and Gynecology, University of Utah, $30 \mathrm{~N}$ \\ 1900 E, 2 B200 SOM, Salt Lake City, UT 84132 \\ (e-mail: zachary.bowman@hsc.utah.edu).
}

\begin{abstract}
Keywords

- placenta accreta

- cesarean delivery

- placenta previa

- risk factors

Objective Placenta previa and prior cesarean delivery are known risk factors for placenta accreta. However, other risk factors have not been identified. Our objective was to examine risk factors for accreta using data collected prospectively in a large multicenter cohort.

Study Design Secondary analysis of women with accreta compared to those without accreta in a large multicenter cesarean delivery cohort. Potential accreta risk factors were examined by univariate and multivariate analyses.

Results In this study, 196 of 73,257 (0.27\%) cesarean deliveries were complicated by accreta. As expected, women with increasing numbers of prior cesareans were more likely to have an accreta $(p<0.001)$, as were women with previa (adjusted odds ratio [OR], 34.9; 95\% confidence interval [CI], 22.4-54.3). We also considered only patients with previa and examined the following variables: maternal demographics, prior cesareans, interval between deliveries, parity, body mass index, tobacco use, and coexisting hypertension or diabetes. In this model, patients with previa and two or three prior cesarean deliveries had an adjusted OR for accreta of $4.9(95 \% \mathrm{Cl}, 1.7-14.3)$ or 7.7 (95\% Cl, 2.4-24.9), respectively. However, no other variables were significantly associated with accreta.

Conclusion Patients with previa have increased risk for accreta that increases with the number of prior cesarean deliveries. However, no other maternal characteristics were associated with accreta.
\end{abstract}

Placenta accreta is characterized by an abnormal adherence of the placenta to the uterine wall. It can be diagnosed clinically when there is a failure of the placenta to normally separate during the third stage of labor, or it can be diagnosed histologically. ${ }^{1}$ The risk for placenta accreta is highest for those women with a placenta previa and prior cesarean delivery, particularly multiple prior cesarean deliveries. ${ }^{2-4}$ Moreover, the incidence of placenta accreta has increased over the last four decades concurrent with an increased

received

August 13, 2013

accepted after revision

October 11, 2013

published online

December 11, 2013 incidence of cesarean delivery. ${ }^{2-5}$ One recent estimate for the incidence of placenta accreta is 1 in 533 pregnancies, ${ }^{6}$ which is increased from approximately 1 in 19,000 in the 1950 s and 1 in 7,000 in the 1970s. ${ }^{7}$

Lack of antenatal suspicion and/or attempted removal of the placenta at the time of delivery can lead to major obstetrical hemorrhage in women with placenta accreta. In turn, this often requires emergency hysterectomy and may result in massive blood transfusion, cystotomy, ureteral
Copyright $\odot 2014$ by Thieme Medical Publishers, Inc., 333 Seventh Avenue, New York, NY 10001, USA. Tel: +1(212) 584-4662.
DOI http://dx.doi.org/ 10.1055/s-0033-1361833. ISSN $0735-1631$. 
injury, infection, venous thromboembolism, and prolonged hospitalization. ${ }^{2}$ It is unclear why some women with risk factors (e.g., previa and prior cesarean) develop accreta while others do not. The identification of additional epidemiologic risk factors may help to explain the pathophysiology of accreta. Several studies have attempted to identify accreta risk factors beyond placenta previa and prior cesarean delivery. ${ }^{3,6,8,9}$ However, these studies are generally limited by small numbers, and no additional risk factors have been consistently identified. Thus, our aim was to examine risk factors for placenta accreta in a large, prospective, multicenter cesarean delivery cohort.

\section{Methods}

We performed a secondary analysis of a de-identified dataset derived from the Eunice Kennedy Shriver National Institute of Child Health and Human Development Maternal-Fetal Medicine Units Network' Cesarean Registry protocol. The Cesarean Registry was a prospective observational study of all women undergoing repeat cesarean section or vaginal delivery after at least one previous cesarean delivery at the participating clinical centers from 1999 through 2002. Women undergoing a primary cesarean delivery were also included during the first 2 years of enrollment. Eight centers participated throughout the study, five centers participated only during the first 2 years, and six centers participated for part of the last 2 years. To be included in the study, delivery also had to result in an infant (live or stillborn) of at least $500 \mathrm{~g}$ or at least 20 weeks gestation by best clinical estimate. Baseline demographic, social, medical, and obstetric data were collected through a chart review on each woman delivering by cesarean or by vaginal birth after cesarean. Information on the delivery course, type of delivery, indication for cesarean delivery, subsequent events, and neonatal data (up to 120 days) were also obtained from the medical records, usually at the time of discharge. Because of the prospective nature of the data collection, treating physicians could be approached to resolve any questions. Full details of the study design and methods have been described previously. ${ }^{10}$

Placenta accreta was defined as a placenta that was adherent to the uterine wall without easy separation. If a pathology report was available, this was given precedence over the clinical findings. ${ }^{11}$ Placenta previa was identified based on the documentation in the medical record of "placenta previa." The position of the placenta within the uterus (e.g., anterior, posterior, lateral, etc.) as well as the type of previa (e.g., complete, partial, or marginal) was not recorded. ${ }^{12}$

For this analysis, women who had placenta accreta (cases) were identified and compared with those who did not having a placenta accreta (controls). Maternal demographic information and characteristics were compared among groups. Categorical variables were compared with $\mathrm{X}^{2}$ or Fisher exact test where appropriate. Continuous variables were compared with Student $t$-test.

To explore additional risk factors for the development of placenta accreta, a generalized linear model that utilized the method of generalized estimating equations was used to model the probability of placenta accreta. Such a model accounts for multiple observations for each subject. A base model was created and a separate model was considered for each variable of interest, while controlling for known risk factors for placenta accreta (i.e., placenta previa and multiple prior cesarean deliveries).

For all statistical tests, two-sided $p$ values are reported, with statistical significance defined as $p<0.05$. SAS 9.2 software (SAS Institute, Cary, NC) was used for analysis.

\section{Results}

In this study, 196 of 73,247 pregnancies (0.27\%) were diagnosed with placenta accreta; 70,498 did not have a documented diagnosis regarding the presence or absence of placenta accreta; 2,553 patients (3.48\%) did not have placenta accreta and comprised the control group. Demographic information and patient characteristics according to the presence or absence of placenta accreta are shown in - Table 1. Overall, the cohort was $40.2 \%$ white, 29.2\% African American, 25.6\% Hispanic, and $5.0 \%$ other race or ethnicity. The groups were similar with regard to race/ethnicity, maternal education, smoking, pre-pregnancy body mass index (BMI), diabetes, and the interval from the prior cesarean delivery until the index cesarean delivery. Women with placenta accreta were more likely to have a placenta previa, a greater number of prior cesarean deliveries, higher parity, and were older compared with those without accreta. They also had a slightly lower delivery BMI and lower rate of chronic hypertension than controls (-Table 1).

- Table 2 shows results of the logistic regression model. In this model, only placenta previa and prior cesarean delivery were significantly associated with placenta accreta. Factors such as maternal age greater than 40 years, parity, hypertension, diabetes, race, pre-pregnancy BMI, interpregnancy interval, smoking, and education were not associated with accreta. Controlling for the number of prior cesarean deliveries, patients with placenta previa were 34.9 times more likely to have placenta accreta than those patients without previa (95\% confidence interval $[\mathrm{CI}], 22.4-54.3$ ). Controlling for previa, patients with one, two, or three prior cesarean deliveries were $2.9,4.6$, and 12.6 times more likely to have an accreta, respectively.

Since placenta previa was so strongly associated with the presence of placenta accreta, we analyzed only the subset of women with placenta previa in an attempt to isolate additional risk factors for accreta. As shown in - Table 3, an initial model was fit with one risk factor for placenta accreta, namely, the number of prior cesarean deliveries. A separate model was then considered for each variable of interest by adding one variable at a time to the base model. The odds ratio (OR) for placenta accreta in the presence of one, two, or three prior cesarean deliveries was $2.6(95 \% \mathrm{CI}$, 0.9-7.0), 4.9 (95\% CI, 1.7-14.3), and 7.7 (95\% CI, 2.4-24.9), respectively. The effect of the number of prior cesarean deliveries was similar across all models (data not shown). No other variables were statistically associated with 
Table 1 Clinical characteristics of women with placenta accreta compared to women without placenta accreta

\begin{tabular}{|c|c|c|c|}
\hline Characteristics & $\begin{array}{l}\text { Cases of accreta } \\
(n=196)\end{array}$ & $\begin{array}{l}\text { Controls } \\
(n=2,553)\end{array}$ & $p$ value \\
\hline Age (y) & $32.8 \pm 5.6$ & $28.9 \pm 6.7$ & $<0.001^{\mathrm{a}}$ \\
\hline \multicolumn{4}{|l|}{ Race/ethnicity } \\
\hline African American & $66(33.7)$ & $963(37.7)$ & \multirow[t]{4}{*}{$0.54^{\mathrm{b}}$} \\
\hline White & $73(37.2)$ & $955(37.4)$ & \\
\hline Hispanic & $43(21.9)$ & $490(19.2)$ & \\
\hline Other & $14(7.1)$ & $145(5.7)$ & \\
\hline \multicolumn{4}{|l|}{ Smoked during pregnancy } \\
\hline Missing & $1(0.5)$ & $4(0.2)$ & \multirow[t]{3}{*}{$0.50^{\mathrm{b}}$} \\
\hline No & $160(81.6)$ & $2,139(83.8)$ & \\
\hline Yes & $35(17.9)$ & $410(16.1)$ & \\
\hline Pre-pregnancy BMI $\left(\mathrm{kg} / \mathrm{m}^{2}\right)$ & $28.0 \pm 7.2$ & $28.2 \pm 8.4$ & $0.76^{\mathrm{a}}$ \\
\hline \multicolumn{4}{|l|}{ Chronic hypertension (treated) } \\
\hline Missing & $1(0.5)$ & $3(0.1)$ & \multirow[t]{3}{*}{$0.016^{c}$} \\
\hline No & $191(97.5)$ & $2,394(93.8)$ & \\
\hline Yes & $4(2.0)$ & $156(6.1)$ & \\
\hline \multicolumn{4}{|l|}{ Diabetes } \\
\hline Missing & $1(0.5)$ & $2(0.1)$ & \multirow[t]{3}{*}{$0.18^{\mathrm{b}}$} \\
\hline No & $178(90.8)$ & $2,247(88.0)$ & \\
\hline Yes & $17(8.7)$ & $304(11.9)$ & \\
\hline \multicolumn{4}{|l|}{ Education } \\
\hline Missing & $78(39.8)$ & $887(34.7)$ & \multirow[t]{3}{*}{$0.25^{\mathrm{b}}$} \\
\hline High school or less & $70(35.7)$ & $1,075(42.1)$ & \\
\hline College & $48(24.5)$ & $591(23.2)$ & \\
\hline \multicolumn{4}{|l|}{ Parity } \\
\hline Missing & $1(0.5)$ & $15(0.6)$ & \multirow[t]{5}{*}{$<0.001^{\mathrm{b}}$} \\
\hline 0 & $10(5.1)$ & $726(28.4)$ & \\
\hline 1 & $44(22.5)$ & $871(34.1)$ & \\
\hline 2 & $58(29.6)$ & $466(18.3)$ & \\
\hline$\geq 3$ & $83(42.4)$ & $475(18.6)$ & \\
\hline \multicolumn{4}{|l|}{ Prior cesarean deliveries } \\
\hline Missing & $1(0.5)$ & $15(0.6)$ & \multirow[t]{4}{*}{$<0.001^{\mathrm{b}}$} \\
\hline 0 & $26(13.3)$ & $1,126(44.1)$ & \\
\hline 1 & $70(35.7)$ & $1,012(39.6)$ & \\
\hline$\geq 2$ & $99(50.5)$ & $400(15.7)$ & \\
\hline \multicolumn{4}{|l|}{ Prior classical hysterotomy } \\
\hline No & $182(92.9)$ & $2,470(96.7)$ & \multirow[t]{2}{*}{0.004} \\
\hline Yes & $14(7.1)$ & $83(3.3)$ & \\
\hline \multicolumn{4}{|l|}{ Placenta previa } \\
\hline Missing & $11(5.6)$ & $148(5.8)$ & \multirow[t]{3}{*}{$<0.001^{b}$} \\
\hline No & $94(48.0)$ & $2,355(92.2)$ & \\
\hline Yes & $91(46.4)$ & $50(2.0)$ & \\
\hline Interval between delivery and last cesarean (y) & $4.9 \pm 4.0$ & $4.7 \pm 3.7$ & $0.54^{\mathrm{a}}$ \\
\hline
\end{tabular}

Note: Data are presented as $n(\%)$ or mean \pm standard deviation.

${ }^{a} p$ values from Student $t$-test.

${ }^{b} p$ values from $x^{2}$ test.

${ }^{c} p$ values from Fisher exact test. 
Table 2 Independent risk factors for placenta accreta identified by logistic regression

\begin{tabular}{|l|l|c|}
\hline Risk factor & Odds ratio (95\% Cl) & $p$ value \\
\hline $\begin{array}{l}\text { Prior cesarean } \\
\text { deliveries (vs. 0) }\end{array}$ & & $<0.001$ \\
\hline 1 & $2.86(1.73-4.72)$ & $<0.001$ \\
\hline 2 & $4.61(2.62-8.11)$ & $<0.001$ \\
\hline$\geq 3$ & $12.57(6.86-23.05)$ & $<0.001$ \\
\hline Placenta previa & $34.91(22.42-54.34)$ & $<0.001$ \\
\hline
\end{tabular}

Abbreviation: $\mathrm{Cl}$, confidence interval.

Table 3 Independent risk factors for placenta accreta among patients with placenta previa

\begin{tabular}{|c|c|c|}
\hline Risk factor & OR $(95 \% \mathrm{Cl})$ & $p$ value \\
\hline \multicolumn{3}{|l|}{ Base model } \\
\hline $\begin{array}{l}\text { Prior cesarean } \\
\text { delivery (vs. 0) }\end{array}$ & & 0.0029 \\
\hline 1 & $2.55(0.93-6.97)$ & 0.068 \\
\hline 2 & $4.93(1.71-14.25)$ & 0.0032 \\
\hline$\geq 3$ & $7.65(2.35-24.89)$ & 0.0007 \\
\hline \multicolumn{3}{|l|}{ Additional models ${ }^{\mathbf{a}}$} \\
\hline Maternal age & $0.98(0.92-1.05)$ & 0.62 \\
\hline $\begin{array}{l}\text { Race (vs. African } \\
\text { American) }\end{array}$ & & 0.59 \\
\hline White & $1.76(0.68-4.52)$ & 0.24 \\
\hline Hispanic & $1.06(0.39-2.89)$ & 0.91 \\
\hline Other & $1.75(0.37-8.35)$ & 0.48 \\
\hline $\begin{array}{l}\text { Smoked during } \\
\text { pregnancy }\end{array}$ & $1.13(0.43-2.94)$ & 0.81 \\
\hline $\begin{array}{l}\text { Pre-pregnancy } \\
\text { BMI }\left(\mathrm{kg} / \mathrm{m}^{2}\right)\end{array}$ & $1.01(0.93-1.10)$ & 0.76 \\
\hline Chronic hypertension & $2.18(0.15-31.43)$ & 0.57 \\
\hline Diabetes & $0.47(0.14-1.58)$ & 0.22 \\
\hline $\begin{array}{l}\text { Education } \\
\text { (vs. elementary) }\end{array}$ & & 0.16 \\
\hline Junior high school & $1.05(0.05-21.07)$ & 0.98 \\
\hline High school & $0.31(0.02-4.15)$ & 0.38 \\
\hline At least some college & $0.94(0.07-13.27)$ & 0.96 \\
\hline Parity (vs. nullipara) & & 0.43 \\
\hline 1 & $0.83(0.10-6.84)$ & 0.86 \\
\hline 2 & $1.52(0.18-13.07)$ & 0.70 \\
\hline$\geq 3$ & $0.54(0.07-4.45)$ & 0.57 \\
\hline $\begin{array}{l}\text { Interval between } \\
\text { delivery and last } \\
\text { cesarean delivery (y) }\end{array}$ & $0.95(0.85-1.07)$ & 0.38 \\
\hline
\end{tabular}

Abbreviations: $\mathrm{BMI}$, body mass index; $\mathrm{Cl}$, confidence interval; OR, odds ratio.

${ }^{\mathrm{a}}$ The effects of previa and prior cesarean delivery were similar across all models, so they are not presented in each additional model. accreta, and all were subsequently removed from the model. Thus, the final model included results for prior cesarean deliveries alone.

In addition, 147 of 196 pregnancies diagnosed with accreta resulted in hysterectomy (75\%). We analyzed only the subset of patients with accreta who underwent hysterectomy and the results were unchanged (data not shown).

\section{Discussion}

Placenta previa and increasing number of prior cesarean deliveries are independent risk factors for placenta accreta. The OR for placenta accreta was 2.6, 4.9, and 7.6 for one, two, or three prior cesarean deliveries, respectively. However, after controlling for placenta previa and prior cesarean delivery, we were unable to identify any other historic or demographic risk factors that were associated with accreta. These included smoking, maternal age, parity, BMI, diabetes, and interval since last delivery.

Others also have noted increasing numbers of cesarean deliveries and previa to be major risk factors for placenta accreta. ${ }^{8,9,13}$ This makes sense given our current concept of the pathophysiology of the condition. In cases of accreta, uterine damage or poor healing due to prior hysterotomy allows the overlying placenta to grow through an absent or damaged Nitabuch layer in the myometrium.

Usta et al noted an increased risk for accreta in women who smoked in a Lebanese cohort of women with placenta previa. ${ }^{8}$ These investigators compared 22 women with previa and placenta accreta with 325 with previa alone. ${ }^{8}$ The OR for accreta in smokers was 3.4 (95\% CI, 1.1-10.2). This is a biologically plausible risk factor since smoking is known to impair wound healing. ${ }^{14}$ In contrast, smoking was not associated with accreta in our cohort or in cohorts in the United Kingdom and Israel. ${ }^{9,13}$ The United Kingdom study included 134 women with accreta and 256 controls. ${ }^{13}$ The Israeli cohort included 130 women with accreta and almost 35,000 controls (no accreta) with cesarean deliveries. ${ }^{9}$ Thus, the latter study was closest in design to ours.

Hypertensive disorders also were associated with accreta in the Lebanese study. ${ }^{8}$ These conditions had an OR for accreta of 13.9 (95\% CI, 2.1-91.2). The authors speculated that hypertension may lead to accreta by causing vascular endothelial damage or that accreta may lead to hypertension by causing abnormal trophoblast invasion. ${ }^{8}$ We found no association between hypertension and accreta. In fact, there was a trend toward more hypertension in women without accreta ( 6.1 vs. $2.0 \%$ in women with accreta). The cohorts from the United Kingdom and Israel also found no significant association between hypertensive disorders and accreta and both noted trends toward more hypertension in women without accreta compared with women with the condition. ${ }^{9,13}$

Advanced maternal age was associated with accreta in the British, Lebanese, and Israeli studies. ${ }^{8,9,13}$ The same was true in our cohort in univariate analysis. However, age was no longer associated with accreta after controlling for previa and prior cesareans. Maternal age was also no longer associated 
with accreta in the Lebanese study after controlling for prior cesarean delivery, ${ }^{8}$ and the risk was modest in the Israeli study (adjusted OR, 1.06; 95\% CI, 1.03-1.09). ${ }^{9}$ Maternal age is a known risk factor for increasing numbers of cesareans and placenta previa. ${ }^{15}$ Thus, it is difficult to determine if it is independently associated with accreta.

Interpregnancy interval was not associated with accreta. A short interpregnancy interval is a risk factor for uterine rupture in women undergoing a trial of labor after prior cesarean ${ }^{16}$ and may lead to suboptimal wound healing. Thus, we hypothesized that it could be associated with accreta. Fitzpatrick et al also found no association between interpregnancy interval and accreta. ${ }^{13}$

We also wondered if increased BMI and/or diabetes would be associated with accreta since they are also linked to poor wound healing. ${ }^{17-19}$ However, we found no association between BMI or diabetes and accreta. Others also found no association between BMI, ${ }^{13}$ diabetes, ${ }^{9}$ and accreta. Recurrent pregnancy loss ${ }^{9}$ and conception by in vitro fertilization ${ }^{13}$ have also been associated with accreta; however, we did not have data regarding these maternal characteristics.

If placenta accreta is suspected, removal of the placenta can be avoided with a planned cesarean hysterectomy performed by experienced personnel. This strategy results in decreased hemorrhage and maternal morbidity. ${ }^{20-22}$ Accordingly, it is desirable to identify women at risk for accreta. Unfortunately, we could not identify additional risk factors for accreta using maternal characteristics.

Strengths of our study include the large number of patients in the cohort (including a large number of patients with placenta accreta), prospective data collection by trained study nurses, and an ethnically and geographically diverse population.

Our study also had several weaknesses. First, our cohort was limited to women with cesarean delivery. Thus, we may have missed risk factors present in women with vaginal births that are not present in those with cesareans, and the results of this analysis apply only to women undergoing a cesarean delivery. Nonetheless, most women with accreta have cesarean deliveries and this is unlikely to meaningfully influence our results. Conversely, our design allowed us to control for the effect of placenta previa by analyzing only women with previa. Second, there were certain variables such as recurrent pregnancy loss that were not collected. Finally, we included women with both clinical and histologic evidence of accreta. However, this is a generally accepted definition that has been used in most studies of accreta. $1,13,21,22$

In conclusion, only placenta previa and multiple prior cesarean deliveries were shown to be significantly associated with placenta accreta. No other risk factors, including maternal age, parity, tobacco use, diabetes, hypertension, smoking, or interpregnancy interval were significant risk factors when controlling for other variables. Given the increased frequency of placenta accreta, these data are clinically relevant for all obstetric care providers. Future research should focus on imaging studies and biomarkers as predictors of placenta accreta.
Note

The title "Risk factors for the development of placenta accreta" was presented at The Society for Gynecologic Investigation 60th Annual Meeting in Orlando, FL, March 23, 2013 (Abstract \#S-189).

\section{Acknowledgments}

We acknowledge the assistance of NICHD, the MFMU Network, and the Protocol Subcommittee in making the database available on behalf of the project. The contents of this article represent the views of the authors and do not represent the views of the Eunice Kennedy Shriver National Institute of Child Health and Human Development Maternal-Fetal Medicine Units (MFMU) Network or the National Institutes of Health.

\section{References}

1 Oyelese Y, Smulian JC. Placenta previa, placenta accreta, and vasa previa. Obstet Gynecol 2006;107(4):927-941

2 Silver RM, Landon MB, Rouse DJ, et al; National Institute of Child Health and Human Development Maternal-Fetal Medicine Units Network. Maternal morbidity associated with multiple repeat cesarean deliveries. Obstet Gynecol 2006;107(6): 1226-1232

3 Miller DA, Chollet JA, Goodwin TM. Clinical risk factors for placenta previa-placenta accreta. Am J Obstet Gynecol 1997;177(1): 210-214

4 Clark SL, Koonings PP, Phelan JP. Placenta previa/accreta and prior cesarean section. Obstet Gynecol 1985;66(1):89-92

5 MacDorman M, Declercq E, Menacker F. Recent trends and patterns in cesarean and vaginal birth after cesarean (VBAC) deliveries in the United States. Clin Perinatol 2011;38(2):179-192

6 Wu S, Kocherginsky M, Hibbard JU. Abnormal placentation: twenty-year analysis. Am J Obstet Gynecol 2005;192(5): 1458-1461

7 Read JA, Cotton DB, Miller FC. Placenta accreta: changing clinical aspects and outcome. Obstet Gynecol 1980;56(1):31-34

8 Usta IM, Hobeika EM, Musa AA, Gabriel GE, Nassar AH. Placenta previa-accreta: risk factors and complications. Am J Obstet Gynecol 2005;193(3 Pt 2):1045-1049

9 Eshkoli T, Weintraub AY, Sergienko R, Sheiner E. Placenta accreta: risk factors, perinatal outcomes, and consequences for subsequent births. Am J Obstet Gynecol 2013;208(3):219. e1-e7

10 Landon MB, Hauth JC, Leveno KJ, et al; National Institute of Child Health and Human Development Maternal-Fetal Medicine Units Network. Maternal and perinatal outcomes associated with a trial of labor after prior cesarean delivery. N Engl J Med 2004;351(25): 2581-2589

11 Gyamfi-Bannerman C, Gilbert S, Landon MB, et al; Eunice Kennedy Shriver National Institute of Child Health and Human Development (NICHD) Maternal-Fetal Medicine Units (MFMU) Network. Risk of uterine rupture and placenta accreta with prior uterine surgery outside of the lower segment. Obstet Gynecol 2012; 120(6):1332-1337

12 Grobman WA, Gersnoviez R, Landon MB, et al; National Institute of Child Health and Human Development (NICHD) MaternalFetal Medicine Units (MFMU) Network. Pregnancy outcomes for women with placenta previa in relation to the number of prior cesarean deliveries. Obstet Gynecol 2007;110(6): $1249-1255$ 
13 Fitzpatrick KE, Sellers S, Spark P, Kurinczuk JJ, Brocklehurst P, Knight $M$. Incidence and risk factors for placenta accreta/increta/percreta in the UK: a national case-control study. PLoS ONE 2012;7(12):e52893

14 Grønkjær M, Eliasen M, Skov-Ettrup LS, et al. Preoperative smoking status and postoperative complications: a systematic review and meta-analysis. Ann Surg 2013

15 Cleary-Goldman J, Malone FD, Vidaver J, et al; FASTER Consortium. Impact of maternal age on obstetric outcome. Obstet Gynecol 2005;105(5 Pt 1):983-990

16 Shipp TD, Zelop CM, Repke JT, Cohen A, Lieberman E. Interdelivery interval and risk of symptomatic uterine rupture. Obstet Gynecol 2001;97(2):175-177

17 Conner SN, Verticchio JC, Tuuli MG, Odibo AO, Macones GA, Cahill AG. Maternal obesity and risk of postcesarean wound complications. Am J Perinatol 2013
18 Alanis MC, Villers MS, Law TL, Steadman EM, Robinson CJ. Complications of cesarean delivery in the massively obese parturient. Am J Obstet Gynecol 2010;203(3):271.e1-271.e7

19 Rehman HU, Mohammed K. Perioperative management of diabetic patients. Curr Surg 2003;60(6):607-611

20 Warshak CR, Ramos GA, Eskander R, et al. Effect of predelivery diagnosis in 99 consecutive cases of placenta accreta. Obstet Gynecol 2010;115(1):65-69

21 Eller AG, Porter TF, Soisson P, Silver RM. Optimal management strategies for placenta accreta. BJOG 2009;116(5): 648-654

22 Eller AG, Bennett MA, Sharshiner M, et al. Maternal morbidity in cases of placenta accreta managed by a multidisciplinary care team compared with standard obstetric care. Obstet Gynecol 2011;117(2, Pt 1)331-337 